\title{
Rhizoctonia solani AG4 associated with foliar blight symptoms on barley in Iran
}

\author{
R. Choupannejad ${ }^{1}$ B. Sharifnabi ${ }^{1}$ A. A. Fadaei Tehrani ${ }^{2} \cdot$ J. Gholami $^{1}$
}

Received: 27 September 2016/Accepted: 11 December 2016/Published online: 16 December 2016

(C) Australasian Plant Pathology Society Inc. 2016

\begin{abstract}
Since June 2011, foliar blight symptoms have been observed in barley fields at Chaharmahal and Bakhtiari, Iran. The symptoms include water soaked spots progressing to elongated stripe and scald like lesions on the leaves and sheaths of barley plants. From cultural and morphological studies and phylogenetic analysis of sequences of the internal transcribed spacer region (ITS) of the ribosomal DNA, the causal agent was identified as Rhizoctonia solani AG4. Pathogenicity tests revealed that $R$. solani AG4 is virulent to barley. To the best of our knowledge this is the first report of $R$. solani AG4 causing foliar disease of barley in Iran.
\end{abstract}

Keywords Pathogenicity test $\cdot$ Molecular identification · Phylogeny $\cdot$ Sequencing $\cdot$ Cultures $\cdot$ Fungal morphology

Barley (Hordeum vulgare) is one of the most important cereal grains in Iran with long historical use as a source of food with high nutritional value. In 2011, approx. 2.5 million tons of barley were produced in Iran (FAO 2011). Generally, the crop yield can be affected by several fungal diseases such as smuts, rusts, leaf scald and mildew. Soil-borne pathogens such as Rhizoctonia solani [teleomorph: Thanatephorus cucumeris] are also known to cause root and crown rot in barley. Rhizoctonia solani, a multinucleate Rhizoctonia spp. is distributed nationwide and causes economic damage to a wide range of crops and ornamental plants. The symptoms are

R. Choupannejad

r.choupannejad@ag.iut.ac.ir

1 Department of Plant Protection, College of Agriculture, Isfahan University of Technology, Isfahan, Iran

2 Department of Plant Protection, College of Agriculture, Shahrekord University, Shahrekord, Iran varied based on environmental conditions, host and growth phase in which the plants become infected, but the most usual symptoms include damping-off or rot and canker on roots and crowns (Erper et al. 2016; Ogoshi 1987; Sneh et al. 1996). However, it can be found on aerial parts of some herbs, ornamentals and several crops (Bai et al. 2015; Garibaldi et al. 2013; Garibaldi et al. 2015; Holcomb and Carling 2002; Valentín Torres et al. 2016). Although many reports of $R$. solani on various hosts exist in Iran, foliar blight on barley has not been reported prior to this publication.

In June and July 2011, foliar blight symptoms were observed in barley fields at Chaharmahal and Bakhtiari, Iran. Symptoms initially developed as small water-soaked spots with light to dark brown margins starting from stems and progressing rapidly as long stripe and scald like lesions on the leaves and sheaths (Fig. 1). No symptoms were seen on the roots. This research was designed (i) to identify the causal agent/s associated with these foliar blight symptoms and (ii) to investigate the virulence of isolated agent/s using pathogenicity tests.

Representative samples exhibiting foliar blight symptoms were collected from barley fields at Chaharmahal and Bakhtiari. Small pieces from the margin of infected tissues were sterilised in $0.5 \%$ sodium hypochlorite $(\mathrm{NaOCl})$ solution for $1 \mathrm{~min}$, followed by washing twice with sterile distilled water, and were then placed on potato dextrose agar (PDA) and incubated at $25{ }^{\circ} \mathrm{C}$ for 7 days. Hyphal tips were subcultured on fresh PDA media to assess morphological properties. All isolates formed white to grey colonies on PDA at $25^{\circ} \mathrm{C}$ (Fig. 2a). The colonies turned to brown with age and produced monilioid cells but no sclerotia. Mycelia were 3$5 \mu \mathrm{m}$ in diameter, branched at right angles with a constriction and septum near the branch origin (Fig. 2b, c). Given these morphological and cultural characteristics, the fungal pathogen was identified as $R$. solani (Sneh et al. 1991). 
Fig. 1 Foliar blight symptoms on barley: a Water soaked spots; $\mathbf{b}$ Stripe and elongated scald like lesions

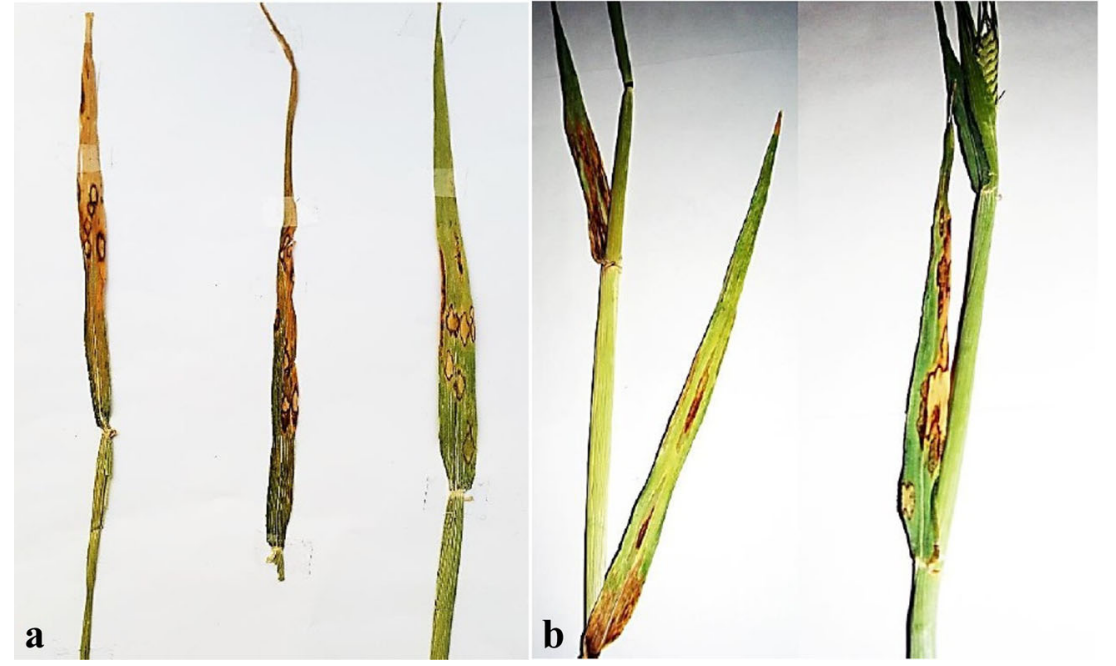

Staining the hyphal cells, using 1\% safranin $\mathrm{O}$ and $3 \%$ $\mathrm{KOH}$ solution (Bandoni 1979), indicated that the cells were multinucleate (3-6 nuclei). An anastomosis interaction assay was assessed via hyphal fusion interactions with standard anastomosis groups (Kronland and Stanghellini 1988). The isolates were anastomosed with several AG4 tester isolates provided from the Fungal Collection, Department of Plant Protection, Isfahan University of Technology, Isfahan, Iran. In vitro possibility of hymenia formation was evaluated by transferring the fungus from 5-day-old enriched medium (potato dextrose malt agar) incubated in darkness at $26{ }^{\circ} \mathrm{C}$ to a poor medium (water agar) as a special sporulation medium. The plates incubated at $26{ }^{\circ} \mathrm{C}$ in darkness for 8 days and then were exposed to $12 \mathrm{~h}$ photoperiod for 10 days (Murray 1982). No teleomorph formation occurred in any of three repeats of the process.

To confirm morphological identification, molecular characterization was also employed. DNA was extracted using 3\% CTAB extraction buffer (Murray and Thompson 1980) and ITS1/4 primers were utilised for
ITS rDNA amplification (White et al. 1990). PCR reactions were performed in $15 \mu \mathrm{l}$ volume containing $15 \mathrm{ng}$ of genomic DNA, 1× Ampliqon Taq DNA Pol. 2× Master mix Red, and $0.4 \mu \mathrm{M}$ of each Primer. A Techne TC-512 thermocycler was used with the following conditions: initial denaturation of $3 \mathrm{~min}$ at $94{ }^{\circ} \mathrm{C}$, 30 cycles of $1 \mathrm{~min}$ at $94{ }^{\circ} \mathrm{C}$, annealing at $59{ }^{\circ} \mathrm{C}$ for $1 \mathrm{~min}$ and $2 \mathrm{~min}$ at $72{ }^{\circ} \mathrm{C}$ with a final extension of $10 \mathrm{~min}$ at $72{ }^{\circ} \mathrm{C}$. Amplified fragments were sequenced and the sequence from isolate LO was deposited in GenBank (accession number KX646540). Our sequences had $99 \%$ similarity with the reference sequence of R. solani AG4 (KC590533.1).

The sequences alignment was performed by ClustalW algorithm and a phylogenetic tree was constructed based on the Neighbor-Joining statistical method (NJ) with 1000 bootstrap replicates using MEGA6 software (Tamura et al. 2013). Tulasnella calospora was used as the out-group. Phylogenetic analysis of isolate LO with other Rhizoctonia spp. revealed that the
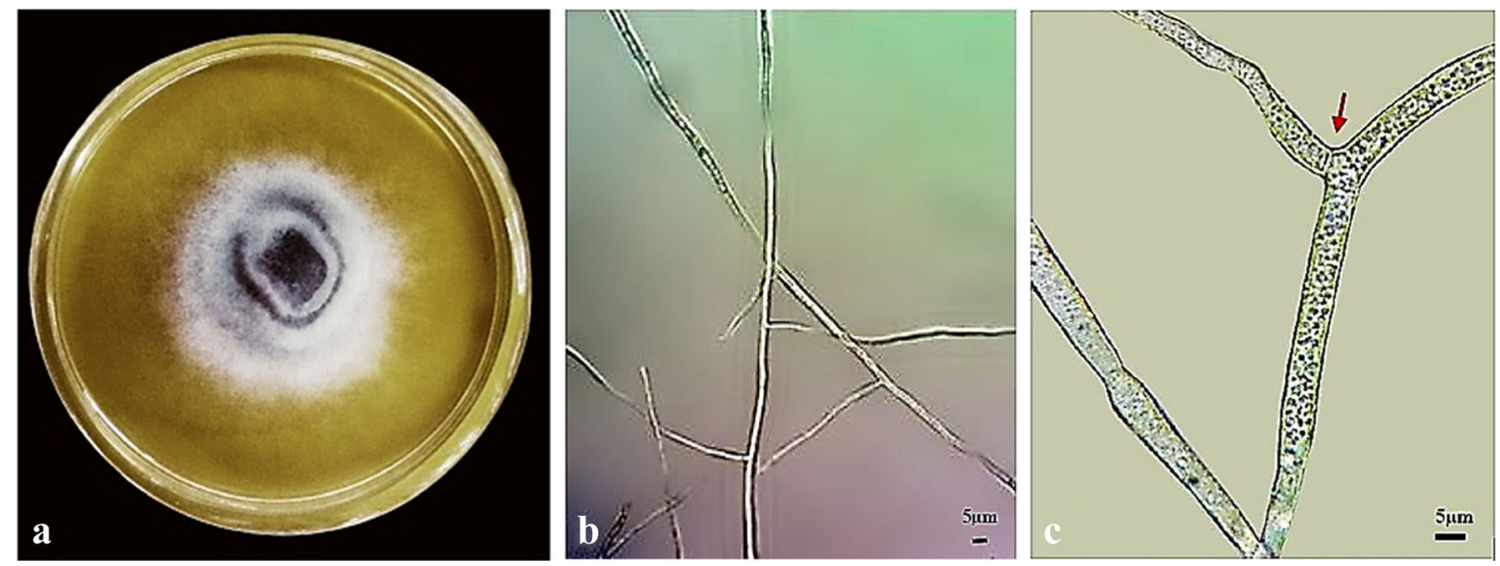

Fig. 2 a Colony of Rhizoctonia solani from isolate LO on PDA, b, c Microscopic Mycelia of Rhizoctonia solani (Right-angled branching and constriction at the base of hyphal branches of isolate LO) 


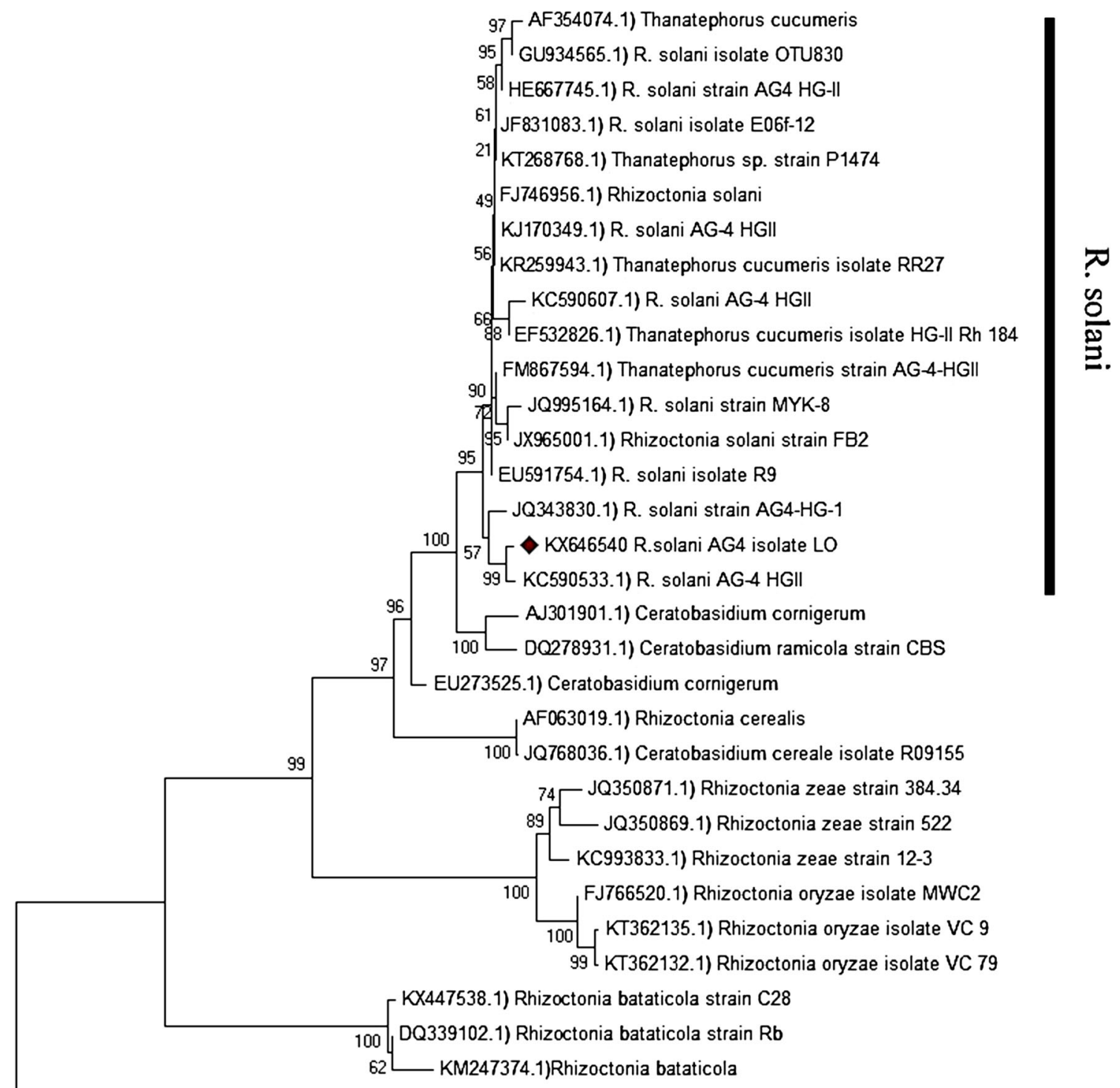

KT601562.1)Tulasnella calospora

Fig. 3 Phylogenetic tree based on Neighbor-Joining analysis of ITS rDNA sequences of Rhizoctonia solani implemented by MEGA6 software. The isolate used in this study marked with red oval. Tulasnella calospora KT601562.1 was used to root the tree

Fig. 4 Pathogenicity test on barley, inoculated with autoclaved wheat grains colonised by Rhizoctonia solani. Foliar symptoms appeared after one month of growth

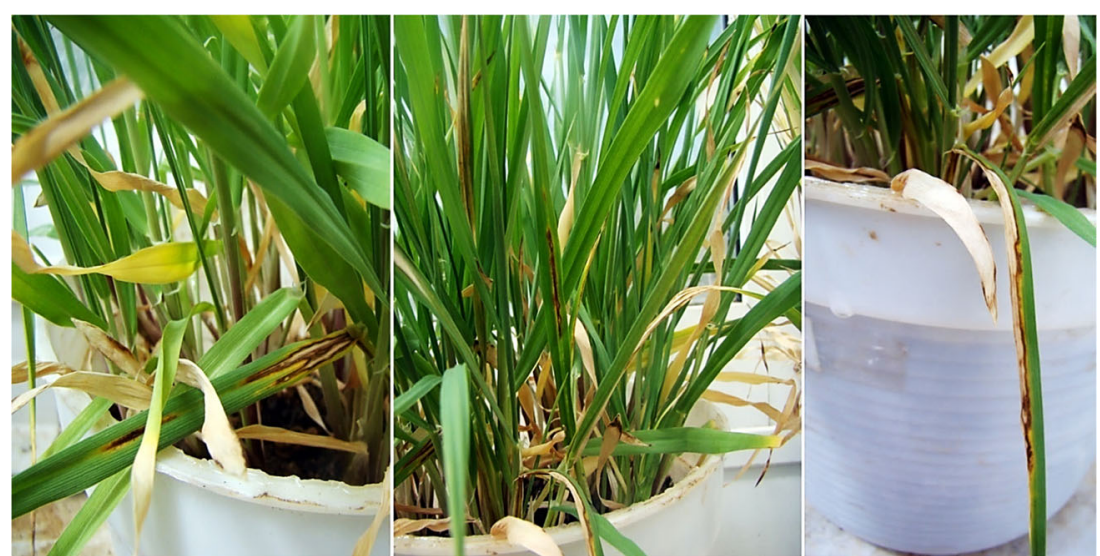


representative sequence from this study clustered with $R$. solani isolates and distinguished it from other Rhizoctonia species. Our isolate shared also a common clade with $R$. solani AG4 HGII (KC590533.1) isolated from wheat in Turkey (Fig. 3). Finally, Isolate LO was deposited in the Iranian Fungal Culture Collection, Iranian Research Institute of Plant Protection, Tehran, Iran (IRAN 2613 C2).

The pathogenicity test was conducted using wheat grains colonised with the fungus as the inoculum. For this, $200 \mathrm{~g}$ wheat grains were soaked in water, autoclaved and mixed with 5-mm-diameter mycelial plugs from 4-day-old PDA cultures. Inoculated wheat grains were mixed with soil $(20 \% \mathrm{~W} / \mathrm{W})$ and surface sterilised ( $2 \%$ sodium hypochlorite) barley seeds were cultivated in five pots (10 seeds per pot) kept at $22{ }^{\circ} \mathrm{C}$ for a month. Non-inoculated autoclaved wheat grains were used as control. After one month, initial symptoms appeared on the leaf margins as chlorotic spots and symptoms progressed as brown necrotic stripe and scald like lesions through the leaves while no symptoms were observed on roots (Fig. 4). Controls showed no symptoms. The observations and results were completely with those in the fields. The fungus was reisolated from infected plants and all characteristics were similar to those of the original samples.

During our surveys, almost $40 \%$ of the barley fields were found to be affected by $R$. solani AG4. More sampling and research are needed to understand the disease status in Chaharmahal and Bakhtiari and other regions of Iran. To date, there is no record of barley foliar blight caused by $R$. solani AG4 in Iran and to the best of our knowledge this is the first report of this pathogen on barley fields in Iran.

Acknowledgements The authors are grateful for financial support of this work by the Research Council of Isfahan University of Technology.

\section{References}

Bai Q, Yang L, Xie Y, Han S (2015) Aerial (web) blight of Begonia semperflorens caused by Rhizoctonia solani AG1-IB in China. Plant Dis 99:1652

Bandoni RJ (1979) Safranin-O as a rapid nuclear stain for fungi. Mycologia 63:873-874

Erper I, Kilicoglu MC, Turkkan M, Onder H (2016) Characterization and pathogenicity of Rhizoctonia spp. isolated from winter squash in the Black Sea region of Turkey. Eur J Plant Pathol 146:683-697

FAO (2011) Food and agriculture organization. The database of annual production. FAOSTAT. Statistical database. http://faostat3.fao. org/compare/E

Garibaldi A, Bertetti D, Pensa P, Poli A, Gullino M (2013) First report of web blight on rosemary (Rosmarinus officinalis) caused by Rhizoctonia solani AG-1-IA in Italy. Plant Dis 97:844

Garibaldi A, Ortu G, Bertetti D, Gullino M (2015) First report of web blight on creeping bellflower (Campanula rapunculoides) caused by Rhizoctonia solani AG 1-IB in Italy. Plant Dis 99:1037

Holcomb G, Carling D (2002) First report of web blight caused by Rhizoctonia solani on Catharanthus roseus in Louisiana. Plant Dis 86:1272

Kronland W, Stanghellini M (1988) Clean slide technique for the observation of anastomosis and nuclear condition of Rhizoctonia solani. Phytopathology 78:820-822

Murray D (1982) A modified procedure for fruiting Rhizoctonia solani on agar. Trans Br Mycol Soc 79:129-135

Murray M, Thompson WF (1980) Rapid isolation of high molecular weight plant DNA. Nucleic Acids Res 8:4321-4326

Ogoshi A (1987) Ecology and pathogenicity of anastomosis and intraspecific groups of Rhizoctonia solani Kuhn. Annu Rev Phytopathol 25: $125-143$

Sneh B, Burpee L, Ogoshi A (1991) Identification of Rhizoctonia species. APS Press, St. Paul

Sneh B, Jabaji-Hare S, Neate S, Dijst G (1996) Rhizoctonia species: taxonomy, molecular biology, ecology, pathology and disease control. Kluwer Academic Press, Dordrecht

Tamura K, Stecher G, Peterson D, Filipski A, Kumar S (2013) MEGA6: molecular evolutionary genetics analysis version 6.0. Mol Biol Evol 30:2725-2729

Valentín Torres S, Vargas MM, Godoy-Lutz G, Porch TG, Beaver JS (2016) Isolates of Rhizoctonia solani can produce both web blight and root rot symptoms in common bean (Phaseolus vulgaris L.). Plant Dis 100:1351-1357

White TJ, Bruns T, Lee S, Taylor J (1990) Amplification and direct sequencing of fungal ribosomal RNA genes for phylogenetics. PCR protocols: a guide to methods and applications 18:315-322 